\begin{tabular}{|c|c|c|c|}
\hline$\Omega$ & 0 & $\equiv$ & 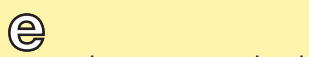 \\
\hline $\begin{array}{l}\text { Irene Steenbruggen }{ }^{1} \text {, } \\
\text { Sharon Mitchell }{ }^{2} \text {, } \\
\text { Brendon Cooper }^{3}\end{array}$ & $\begin{array}{l}\text { 'Isala Klinieken, Zwolle, The } \\
\text { Netherlands } \\
{ }^{2} \text { ERS Headquarters, Lausanne, } \\
\text { Switzerland } \\
{ }^{3} \text { Lung Function and Sleep, Lung } \\
\text { Investigation, University } \\
\text { Hospitals Birmingham NHS } \\
\text { Foundation Trust, Queen } \\
\text { Elizabeth Hospital Birmingham, } \\
\text { Birmingham, UK }\end{array}$ & $\begin{array}{l}\text { I. Steenbruggen: Isala } \\
\text { Klinieken, Groot Wezenland } \\
\text { 20, } 8011 \text { JW Zwolle, } \\
\text { The Netherlands }\end{array}$ & i.steenbruggen@isala.nl \\
\hline
\end{tabular}

\title{
ERS European Spirometry Train-the- Trainer programme: good trainers are made, not born
}

\section{Introduction}

The most commonly used pulmonary function test is spirometry. This test measures how much air you can breathe in and out and how quickly you can move air out of your lungs. Spirometry is a powerful tool for the diagnosis and monitoring of asthma and COPD and its use is recommended by international guidelines for asthma and COPD [1-3]. The updated NICE guidelines of 2010 state that all health professionals managing patients with COPD should have access to spirometry and must be trained and competent in its use and interpretation. The increased availability of spirometers has led to improved access in primary care. Spirometry appears to be a simple test; however, it depends upon the quality of equipment and patient cooperation and, foremost, requires highly trained and competent staff to perform and evaluate the test correctly.

\section{Spirometry training practices in Europe}

Many European countries have shown a growing interest to regulate the quality of spirometry education.

The American Thoracic Society/European Respiratory Society (ERS) Task Force on
Standardisation of Lung Function Testing [4] recommends a standard training similar to the National Institute for Occupational Safety and Health-approved spirometry programme in the USA, which includes the fundamentals of spirometry standards and hands-on training. Competency is demonstrated by passing a written and practical examination in the presence of an experienced instructor.

To assess the current situation of spirometry training in Europe, an online survey was carried out in 2008 by the ERS. This survey showed that, due to a lack of well-structured training opportunities, $94 \%$ of the respondents identified a need for standardised training courses.

The results of this survey launched the European Spirometry Driving Licence (ESDL) HERMES (Harmonised Education of Respiratory Medicine in European Specialties) project. The aim of the Spirometry HERMES Task Force was to improve quality and standardisation of spirometry testing [5].

As part of Task Force developments, a subsequent survey carried out in February 2012 reinforced the need to address Europe's inconsistencies in spirometry training, and to produce high-quality standards for spirometry training courses to follow. 305 participants were surveyed on spirometry testing and training in specific countries. Of the 305 participants surveyed, over $87 \%$ perform spirometry testing
Statement of interest S. Mitchell is an employee of ERS. 
in their countries. However, when asked about spirometry training, in line with the 2008 ERS survey, on-the-job training remains the most dominant training method across countries.

\section{What spirometry training methods are used in your country?}

At this moment in Europe, many spirometry courses are available but content and duration differ widely (ERS Surveys on Spirometry training practices 2008, 2012). In a few countries, spirometry training is approved by a professional body and these are often excellent training programmes. However, in many countries there is clearly room to raise spirometry skill levels to ensure that patients are appropriately tested by competent staff.

The Spirometry HERMES Task Force published a complete spirometry training programme in March 2011 [5, 6]. This training programme is divided into two specific parts: Part I covers knowledge and basic skills in spirometry testing and Part II addresses knowledge and competence in spirometry measurement and requires participants to complete a spirometry workbook, calibration logs and a portfolio of spirometry tests. Participants will be requested to complete assessments at each phase.

Because of the need for structured training, the ERS has now developed a "train-the-trainer" educational programme to disseminate this structured spirometry training across Europe.

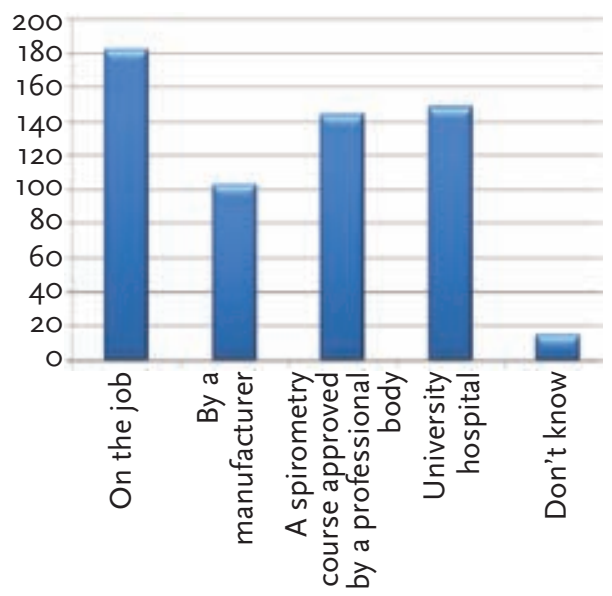

Figure 1

How is spirometry taught in your country?

\section{Train-the-trainer courses}

In fact all health professionals are teaching every day as part of their positions. They contribute to the education and training of students, colleagues and patients. Doctors and other health professionals share skills and experience within their professional group. It is undeniable that content knowledge is indispensable for effective teaching; however, teachers must also be competent to apply this knowledge in their teaching. Referring to J. Busari's (ERS medical education advisor) lecture during the ERS medical education seminar in Dublin 2011, 'instructors should be equipped with certain basic competencies that include:

- Knowledge of how to teach (didactic knowledge)

- Knowledge of the general principles of education and

- Proficiency in the domain-specific knowledge/ competencies'

Although health professionals provide teaching and training, they usually receive no formal training in this area [7]. In support of this statement, the 2008 and 2012 Spirometry training practices surveys highlighted that although $64 \%$ of respondents teach how to perform spirometry in their countries, $72 \%$ of the respondents reported that either there was not a course available, or they were not aware of a course available to equip trainers with the essential competencies and tools to teach spirometry.

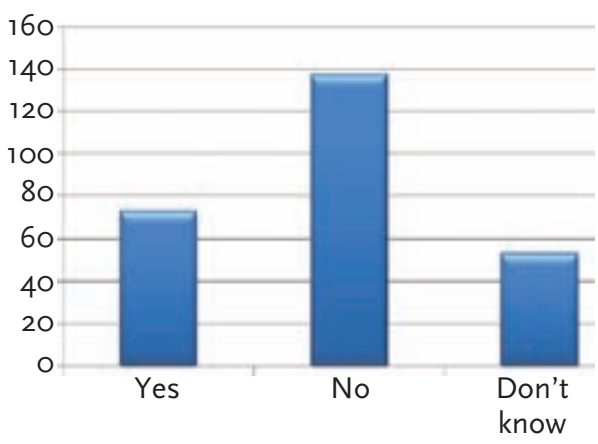

Figure 2

Are you aware of a course which provides trainers with the skills to deliver effective spirometry training sessions? 
Now, formal medical education for doctors and health professionals is regarded as essential to enhance teaching effectiveness, as highlighted by the General Medical Council [8]. Health professional educators are expected to undertake courses that improve presentation and feedback skills, teaching techniques, learning styles and how to effectively assess knowledge and competence.

Because teaching roles are expected of health professionals, staff must be equipped and supported to provide good quality education [8] Teaching responsibilities include appropriate preparation and didactic and content knowledge, but also enthusiasm, ability to stimulate students, commitment to teaching and reflection on teaching skills.

Train-the-trainer courses (or teach-theteacher courses) will offer the opportunity to share experiences, expertise and knowledge and will increase effectiveness as an educator. It will improve training techniques and provide the competencies and tools to deliver effective training. The Spirometry HERMES Task Force has recognised that teacher training is an essential tool to ensure the successful dissemination of a European spirometry training programme across Europe.

\section{The ERS European spirometry train-the-trainer programme}

To date the Task Force has completed a number of key phases (fig 3). A key component in this project is the development of a specific train-the-trainer course for spirometry training. Not only will core topics on teaching and learning styles, presentation and facilitation skills be covered, but this training will also specifically address training of spirometry, key problems areas to be aware of, management of small group hands on learning sessions, and use of spirometers in training.

The principle of this train-the-trainer approach is to provide training and supply educational materials during a highly participative one-day course. This learning programme and supporting educational materials can then be further applied by local trainers to share the acquired knowledge and skills to a wide range of participants, with the aim of improving the quality of spirometry testing.
The first spirometry Train-the-Trainer will take place as an educational Postgraduate Course at the ERS Annual Congress, Vienna on September 1st 2012. Registrations are now open at www.erscongress2012.org.

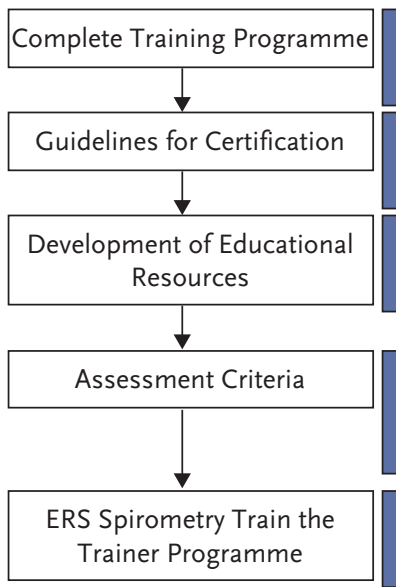

Completed Training Programmes for Part I and Part II spirometry training published in Breathe March 2011

Completed guidelines for the certification of spirometry training programmes in Breathe March 2011

The Task Force is currently finalising the development of educational materials required for Spirometry Training

Assessment criteria for the knowledge test and practical assessment will be developed between December 2011 and September 2012

The first Spirometry Train-the-Trainer course will be held as a Post Graduate Course, ERS Congress, Vienna 2012.

Figure 3

Key phases of the Task Force.

By attending this training, participants will have an understanding of each of the key subject areas including

1. the ERS spirometry training process;

2. techniques of teaching and learning styles;

3. presentation and facilitation styles;

4. overcoming resistance during training;

5. discussion and feedback skills required;

6. ERS spirometry-specific teaching and training styles;

7. assessment processes for the ERS spirometry training programme and awarding the European Spirometry Driving Licence;

8. criteria required to organise an ERS spirometry training course.

Participants will also be required to complete pre-requisites prior to attending the course programme

1. All participants must be familiar with the ERS HERMES spirometry documentation before attending the course;

2. All participants must prepare written feedback of a spirometry workbook;

The programme will be delivered by dedicated educators together with experts in spirometry.

The course is aimed at anyone who teaches spirometry to colleagues on the job, or in a structured training programme. 


\section{Future challenges}

The European Spirometry Driving Licence HERMES project provides a platform from which to move on to higher-level education in respiratory physiology. This could result in a European Lung Function Driving Licence. This more advanced driving licence will address lung function measurements like the measurement of lung volumes, gas transfer, respiratory muscle assessment, challenge testing, exhaled markers and blood gases.

Because knowledge and techniques in this field are rapidly expanding, and to ensure that patients receive the best quality of care, all staff performing lung function tests should regularly update knowledge and skills.

\section{Conclusion}

In order to use spirometry testing for diagnosing and monitoring of patients, high quality testing is vital. The quality of current and future delivery of spirometry is mainly dependent on the quality of education. Therefore, an interactive one-day Train-theTrainer course has been specifically designed to give anyone who teaches spirometry, the practical techniques, knowledge, skills and confidence necessary to deliver effective spirometry training.

Although there are outstanding teachers who have never taken a course on how to teach, anyone will benefit from training in teaching.

\section{References}

1. Global Initiative for Asthma (GINA) 2011. Available from: www.ginasthma.org Date last accessed: 29 February 2012; date last updated: December 2011

2. National Clinical Guideline Centre. Chronic obstructive pulmonary disease: management of chronic obstructive pulmonary disease in adults in primary and secondary care 2010. Available from: http://guidance. nice.org.uk/CG101/Guidance/pdf/English Date last accessed: 29 February 2012; date last updated: 18 January 2012.

3. Global Strategy for the Diagnosis, Management and Prevention of COPD 2011. Global Initiative for Chronic Obstructive Lung Disease (GOLD) 2011. Available from: www.goldcopd.org/uploads/users/files/ GOLD_Report_2011_Feb21.pdf Date last accessed: 24 February 2012; date last updated: December 2011.

4. Miller MR, Crapo R, Hankinson J, et al. General considerations for lung function testing. Eur RespirJ 2005; 26: 153-161.
5. Steenbruggen I, Mitchell S, Severin T, et al. Harmonising spirometry education with HERMES: Training a new generation of qualified spirometry practitioners across Europe. Eur Respir J 2011; 37: 479-481.

6. Cooper BG, Steenbruggen I, Mitchell S, et al. HERMES Spirometry: the European Spirometry Driving Licence. Breathe 2011; 7: 258-275.

7. MacDougall J, Drummond MJ. The development of medical teachers: an enquiry into the learning histories of 10 experienced medical teachers. Med Educ 2005; 39: 1213-1220.

8. General Medical Council. Tomorrow's doctors. Outcomes and standards for undergraduate medical education. Available from: www.gmc-uk.org/ TomorrowsDoctors_2009.pdf_39260971.pdf Date last accessed: 5 March 2012; date last updated: September 2009. 